Joses of 100 and $200 \mathrm{mg}$ norethandrolone were necessary to prevent occurrence of cystic follicles after stoppage of the treatment. Using these doses, synchronization of oestruses over a period of 72 hrs was obtained in 65 per cent and 75 per cent of the treated female, the others exhibiting oestrus later ( $48 \mathrm{hrs})$. 83.3 per cent and 75 per cent of the treated sows were pregnant. Fertility was comparable with that of the controls (9o per cent). RU 2267 doses of $20 \mathrm{mg} / \mathrm{day} / \mathrm{sow}$ were necessary to prevent formation of cystes. An excellent oestrus synchronization over 72 hrs was obtained in 98 per cent of the animals. 50 to 60 per cent of the sows were pregnant at 30 days. Supply of PMSG and HCG when the treatment stopped did not change the rate of pregnant sows.

\title{
Comparison of some techniques of pregnancy diagnosis in the sow
}

\author{
M. J. BOSC, Françoise MARTINAT-BOTTE (1) et Agnès NICOLLE (2) \\ (1) T.T.P., I 49, rue de Bercy, 75579 Paris Cedex I2 \\ (2) Station de Physiologie de la Reproduction, I.N.R.A., 3738o Nouzilly (France)
}

The accuracy of pregnancy diagnosis depends on fertility and thus varies with the exper1mental conditions. For preventing this problem, a method is proposed based on the Doppler ultrasonic technique and use of a boar. According to results obtained, this procedure gives more exact results than those obtained by determination of the plasma level of progesterone, vaginal biopsy, cchography or simple supervision of the animals. Moreover, efficiency of a diagnosis can be defined as the product of total accuracy into the difference between duration of pregnancy and time of diagnosis. This method shows that use of a boar remains the most suitable method for diagnosis of pregnancy.

\section{Use of prostaglandins at the time of parturition in the sow. Results in field conditions}

M. J. BOSC (1), Françoise MARTINAT-BOTTE $\left({ }^{(2}\right)$, G. GROUZELLE et B. HURAULT ( $\left.{ }^{3}\right)$

(1) Station de Physiologie de la Reproduction, I.N.R.A., 37380 Nouzilly (France)

(') I.T.P., r49, nue de Bercy, 75579 Paris Cedex r2

(3) S.C.E.A.P., Nohant-en-Gout, I8ooo Bourges (France)

Two possibilities of use of an analogue of prostaglandin $F_{2} \alpha$ at the time of parturition have been tested in field conditions. 229 animals were treated. The results show that farrowings can be grouped in 2 or 3 days with suppression of parturition during the week-end. The secondary effects observed in piglets or in sows allow to consider the systematic application of this kind of compound. 